\title{
ЗАСТОСУВАННЯ АРТЕРІАЛЬНОЇ ОСЦИЛОГРАФІЇ ДЛЯ ОЦІНКИ ЯКОСТІ АДАПТАЦІЇ СЕРЦЕВО-СУДИННОЇ СИСТЕМИ ДО ЗМІНИ ПОЛОЖЕННЯ ТІЛА (ОРТОПРОБА)
}

\author{
Д. В. Вакуленко, Л. О. Вакуленко, О. В. Кутакова ${ }^{1}$ \\ ДВНЗ «Тернопільський державний медичний університет \\ імені І. Я. Горбачевського МОЗ України» \\ ${ }^{1}$ Комунальна установа «Центральна районна лікарня» Житомирської районної ради
}

\begin{abstract}
Розглянуто застосування осцилографічного методу, артеріальних осцилограм (за морфологічним, часовим та спектральним методами). Вказаний метод надає можливість оцінити стан специфічного (вазомоторного, пов'язаного з регуляцією судинного тонусу) і неспецифічного симпатоадреналового механізмів адаптації організму до активної ортостатичної проби. Застосування осцилографічного методу під час проведення ортостатичної проби дозволяє раннє виявлення донозологічних і преморбідних станів та оцінку резервних можливостей організму, що допоможе лікарю більш ефективно спланувати профілактичний, діагностичний та терапевтичний процес.
\end{abstract}

Ключові слова: артеріальна осцилографія, проба Руф'є, ортостатична проба, механізми адаптації.

\section{ПРИМЕНЕНИЕ АРТЕРИАЛЬНОЙ ОСЦИЛЛОГРАФИИ ДЛЯ ОЦЕНКИ КАЧЕСТВА АДАПТАЦИИ СЕРДЕЧНО-СОСУДИСТОЙ СИСТЕМЫ К ИЗМЕНЕНИЮ ПОЛОЖЕНИЯ ТЕЛА (ОРТОПРОБА)}

\author{
Д. В. Вакуленко, Л. А. Вакуленко, А. В. Кутакова ${ }^{1}$ \\ ГВУЗ «Тернопольский государственный медицинский университет \\ имени И. Я. Горбачевского МЗ Украины» \\ ${ }^{1}$ Коммунальное учреждение «Центральная районная больница» \\ Житомирского районного совета

\begin{abstract}
Рассмотрено применение осциллографического метода, артериальных осциллограмм (морфологическим, временным и спектральным методами). Указанный метод дает возможность оценить состояние специфического (вазомоторного, связанного с регуляцией сосудистого тонуса) и неспецифического симпатоадреналового механизмов адаптации организма к активной ортостатической пробе. Применение осциллографического метода при проведении ортостатической пробы дает возможность раннего выявления донозологических и преморбидных состояний и оценки резервных возможностей организма, что поможет врачу более эффективно спланировать профилактический, диагностический и терапевтический процесс.
\end{abstract}

Ключевые слова: артериальная осциллография, проба Руфье, ортостатическая проба, механизмы адаптации.

\section{THE USE OF ARTERIAL OSCILLOGRAPHY TO ASSESS THE QUALITY OF ADAPTATION OF THE CARDIOVASCULAR SYSTEM TO CHANGES IN BODY POSITION (ORTHOSTATIC TEST)}

\section{V. Vakulenko, L. O.Vakulenko, O. V. Kutakova}

SHEE "I. Horbachevsky Ternopil State Medical University of the Ministry of Health of Ukraine"

${ }^{1}$ Municipal Institution "Central District Hospital" Zhytomyr District Council

It is considered the application of oscillographic method, arterial oscillograms (at morphological, temporal and spectral methods). Indicated method makes it possible to assess the condition of specific (related to the regulation of vascular tone) and sympathoadrenal nonspecific mechanisms of adaptation on active orthostatic test. Application of oscillographic method during orthostatic test enables early detection of prenosological and premorbid conditions and assessing the reserve capacity of the organism to help doctor better plan preventive, diagnostic and therapeutic process.

Keywords: arterial oscillography, Ruf'ye test, orthostatic test, mechanisms of adaptation.

(C) Д. В. Вакуленко, Л. О. Вакуленко, О. В. Кутакова 
Вступ. Сучасні інформаційні технології широко втілюються в практику охорони здоров'я, що сприяє ранньому виявленню захворювань, вчасній профілактиці та ефективному лікуванню. Це стосується найбільш поширених захворювань людства, так званих неінфекційних патологій (захворювання серцево-судинної, легеневої системи, цукровий діабет, онкологічні та інші захворювання). На долю цих патологій перепадає близько 68 \% всіх смертей у світі [8]. Тому сьогодні особливо важливо впроваджувати сучасні технології для раннього виявлення донозологічних і преморбідних станів, оцінювання резервних можливостей організму, що допоможуть лікарю більш ефективно спланувати профілактичний, діагностичний та терапевтичний процес.

Функціональні резерви організму можуть бути оцінені кількісно: шляхом визначення різниці між рівнем функціонування у стані спокою і при максимально допустимому рівню функції. Незважаючи на наявність великої кількості навантажувальних тестів, вибір їх для використання масових донозологічних обстежень населення досить обмежений. Це зумовлено обмеженнями в часі обстеження, наявністю обладнання, станом обстежуваних. Останнє пов'язане зі зниженням рівня функціональних можливостей обстежуваних, особливо старшого віку [3].

Серед функціональних тестів найбільш простою і доступною пробою, яка дозволяе оцінити функціональні резерви механізмів регуляції кровообігу, $є$ активна ортостатична проба. При цьому орто статичний вплив (гравітаційне навантаження) безпосередньо спрямований на механізм регуляції кровообігу і практично зазвичай не впливає на енергетичні та метаболічні процеси в організмі [3]. В нормі у відповідь на ортостаз відбувається перерозподіл значної частини об'єму циркулюючої крові з короткочасним застоєм ії в ємкісних судинах. Це призводить до зниження притока крові у праві відділи серця і зменшення серцевого викиду. Внаслідок цього знижується артеріальний тиск, запускаються механізми регуляції кровообігу.

Р. М. Баєвський звертає увагу на те, що реакція організму на ортостатичний вплив містить два компоненти: специфічний і неспецифічний. Перший вазомоторний, пов'язаний з регуляцією судинного тонусу. Він реалізується через вазомоторний центр і заключається у його активації у відповідь на ортостатичний вплив. Другий - зумовлений мобілізацією необхідних інформаційних і енергетичних резервів, що супроводжується механізмами активації симпатичного відділу вегетативної нервової системи, такими ж, як і при відповіді організму на будь-які інші стресорні впливи. Обидва ці механізми при орто статичних впливах забезпечують єдину відповідь організму, адекватне новим умовам кровопостачання тканин та органів. їхній стан добре відображається показниками кардіоінтервалів [2]. Застосування осцилографічного методу дозволяє оцінити роль периферійного кровообігу в ортостатичній пробі та механізми його регуляції $[4,5]$.

Мета роботи: вивчити й оцінити функціональну здатність системи кровообігу адаптуватися до компресії судин плеча при вимірюванні артеріального тиску у стані спокою та після активної ортостатичної проби за допомогою запропонованих авторами роботи інформаційних технологій морфологічного, часового, спектрального аналізу артеріальних осцилограм. Отримані результати порівняти 3 такими ж, отриманими після виконання 30 присідань за 45 сек. (проба Руф'є).

Матеріали та методи дослідження. Обстежено дві групи молодих осіб чоловічої та жіночої статі віком 18-22 років без скарг на стан здоров'я. 1-ша група включала 25, 2-га - 68 здорових осіб. Обстеження включало вимірювання артеріального тиску за допомогою приладу ВАТ41-2, здатного реєструвати значення тиску в манжеті в період зростання компресії та експортувати отримані значення для подальшого аналізу, який проводився за допомогою запропонованих авторами спеціальних комп'ютерних програм. Отримані осцилограми підлягали морфологічному, часовому та частотному аналізу.

Результати та їх обговорення. Для зручності порівняння початкового аналізу використано динаміку часового та спектрального аналізу осцилограм при проведенні проби Руф'є. Часовий аналіз проведено шляхом визначення тривалості інтервалів між вершинами осциляцій в процесі зростання компресії плеча за максимальними та мінімальними екстремумами.

3 цією метою використані прийняті в електрокардіографії такі показники: SDSD, NN50, pNN50, Mo, AMo, BP, Si, BПP, IH, HRV-індекс, RMSSD, RR

std, а також power_osc_stdev - середнє квадратичне відхилення амплітуд. їхні середні значення: SDSD

- $(0,45 \pm 0,02) \mathrm{c}, \mathrm{RMSSD}-(0,36 \pm 0,2) \mathrm{c}, \mathrm{pNN} 50$ - $10,6 \pm 0,02$, Mo - $(0,87 \pm 0,02)$ c, AMo - $(37,1 \pm$ $1,1) \%$, BP - $0,6 \pm 0,01$; IVR $-75,2 \pm 7,6$, VPR - 0,75 $\pm 0,03, \mathrm{IN}-32,3 \pm 2,9, \mathrm{HVR}$-індекс - 29,2 $\pm 0,12$. 
Таблиияя 1

Динаміка показників варіаційної пульсометри, часового, спектрального аналізу осцилограм при проведенні активної ортостатичної проби

\begin{tabular}{|l|c|c|c|c|c|}
\hline \multicolumn{5}{|c|}{ Динаміка досліджуваних показників осцилограм } \\
\hline \multicolumn{2}{|c|}{\begin{tabular}{l} 
Показники, динаміка яких відповідає динаміці \\
\multicolumn{2}{|c|}{ При пробі Руф'є }
\end{tabular}} & \multicolumn{3}{c|}{ призники, динобі Руф’є } \\
\hline SDSD-pos & $0,142 \pm 0,008$ & $0,125 \pm 0,008$ & SDSD-neg & $0,365 \pm 0,012$ & $0,380 \pm 0,012$ \\
\hline NN50-pos & $43,95 \pm 1,329$ & $40,34 \pm 1,293$ & NN50-neg & $62,16 \pm 1,018$ & $69,53 \pm 0,991$ \\
\hline Mo-pos & $1,04 \pm 0,012$ & $0,88 \pm 0,012$ & AMo-pos & $48,07 \pm 1,363$ & $31,01 \pm 1,354$ \\
\hline Mo-neg & $1,05 \pm 0,013$ & $0,86 \pm 0,013$ & AMo-neg & $41,04 \pm 1,152$ & $24,99 \pm 1,134$ \\
\hline HVR-index-pos & $31,039 \pm 0,713$ & $37,020 \pm 0,694$ & BP-pos & $0,29 \pm 0,008$ & $0,44 \pm 0,008$ \\
\hline HVR-index-neg & $30,06 \pm 0,743$ & $41,23 \pm 0,724$ & BP-neg & $0,68 \pm 0,012$ & $0,75 \pm 0,012$ \\
\hline BPM-ЧCC & $62,22 \pm 0,793$ & $71,55 \pm 0,771$ & IVR-pos & $260,7 \pm 15,694$ & $95,74 \pm 15,412$ \\
\hline RMSSD 0,43 & $0,142 \pm 0,008$ & $0,125 \pm 0,008$ & IVR-neg & $75,56 \pm 3,779$ & $36,34 \pm 3,703$ \\
\hline VPR-pos & $0,29 \pm 0,008$ & $0,54 \pm 0,008$ & IN-pos 80-150 & $148,3 \pm 10,53$ & $42,35 \pm 10,333$ \\
\hline VPR-neg & $0,69 \pm 0,015$ & $1,04 \pm 0,015$ & IN-neg & $43,01 \pm 2,546$ & $17,35 \pm 2,493$ \\
\hline & & & Total-04 & $1100 \pm 134,2$ & $720 \pm 113,4$ \\
\hline & & & VLF & $1919 \pm 231,8$ & $1200 \pm 160,2$ \\
\hline & & & LF & $46 \pm 3,5$ & $11 \pm 0,4$ \\
\hline & & & HF & $1480 \pm 342,5$ & $1200 \pm 231,8$ \\
\hline
\end{tabular}

Порівняно до отриманих з літературних джерел [1] показників, зареєстрованих при аналізі електрокардіограми (ЕКГ), наші дані вкладаються в діапазон їхніх коливань: Мо - $(0,9 \pm 0,03)$ c, АМо - $(37,5$ $\pm 3) \%$, RMSSD - $(0,43 \pm 0,19)$ c, pNN50 - 18,1 \pm 13 .

Зразу після навантаження в обстежених на максимальних екстремумах зареєстровано достовірне зниження показників SDSD, pNN50, Mo (P <0,001) та зростання показників AMo $(\mathrm{P}<0,01)$, IVR, IN та HVR-індексу, середнього квадратичного відхилення амплітуд осциляцій (P < 0,001), що (за аналогією з ЕКГ) свідчить про зростання симпатико-адренергічних впливів та підвищення рівня централізації керування системою кровообігу [6].

Спектральний аналіз. Фізичне навантаження сприяло підвищенню показників відсотка потужності спектру низьких (LF\%, P < 0,01) та наднизьких (VLF_P\%, P < 0,01) частот, потужності спектру тета-ритму $(\mathrm{P}<0,01)$ та зниженню рівня високих $(\mathrm{HF} \%, \mathrm{P}<0,01)$ частот у загальному спектрі частот. Це свідчить про збільшення активності симпатичного відділу вегетативної нервової системи, активацію симпатичного судинного центру; спектру VLF - про збільшення активності центру терморегуляції та енергометаболічного обміну, а тета-ритму - про зростання централізації впливу на кровообіг [7].
Ортостатична проба. У 25 осіб вивчено реакцію на зміну положення тіла (ортопроба). Досліджувані показники обстежених 1-ї групи у стані спокою достовірно не відрізнялись від аналогічних показників осіб 2-ї групи. Проте ортостатична проба не викликала очікуваної динаміки (подібної до 20 присідань) досліджуваних показників (табл. 1).

Аналіз зображених у табл. 1 результатів осіб 1-і групи спрямував на наступні роздуми.

Особливості оцінки вихідного стану перед проведенням проби Руф'є.

1. Обстеженню підлягали молоді, без скарг на стан здоров'я особи, які займаються спортом.

2. Відсутність вікових змін з боку системи кровообігу.

3. Отримані показники вихідного стану відповідають загальноприйнятим в літературі $[1,2]$ та мають високий рівень кореляційного зв'язку 3 показниками варіабельності серцевого ритму синхронно записаної авторами ЕКГ.

Особливості реакції на фізичне навантаження (проба Руф'є).

1. Динаміка показників є достовірною і співпадає 3 вказівками інших авторів про характер реакції на стресову ситуацію: зростання симпатико-адренергічних впливів та 
підвищення рівня централізації керування системою кровообігу.

2. Отримані показники мають високий рівень кореляційних зв'язків 3 показниками варіабельності серцевого ритму, зареєстрованими до та після проби Руф'є.

3. Вивчення досліджуваних показників через 2 хв відпочинку засвідчило їх відновлення. В окремих осіб вони виявились навіть нижчими, ніж до навантаження, що вказує на високий рівень адаптаційних можливостей системи кровообігу обстежених.

Усе відмічене дає право допустити достовірність отриманих результатів реакції системи кровообігу на функціональну пробу Руф'є і можливість використання іiі для порівняльного аналізу.

Характеристика осіб 1-ї групи.

1. Вік обстежених відповідає віку представників 2-ї групи.

2. Обстежені також займаються спортом.
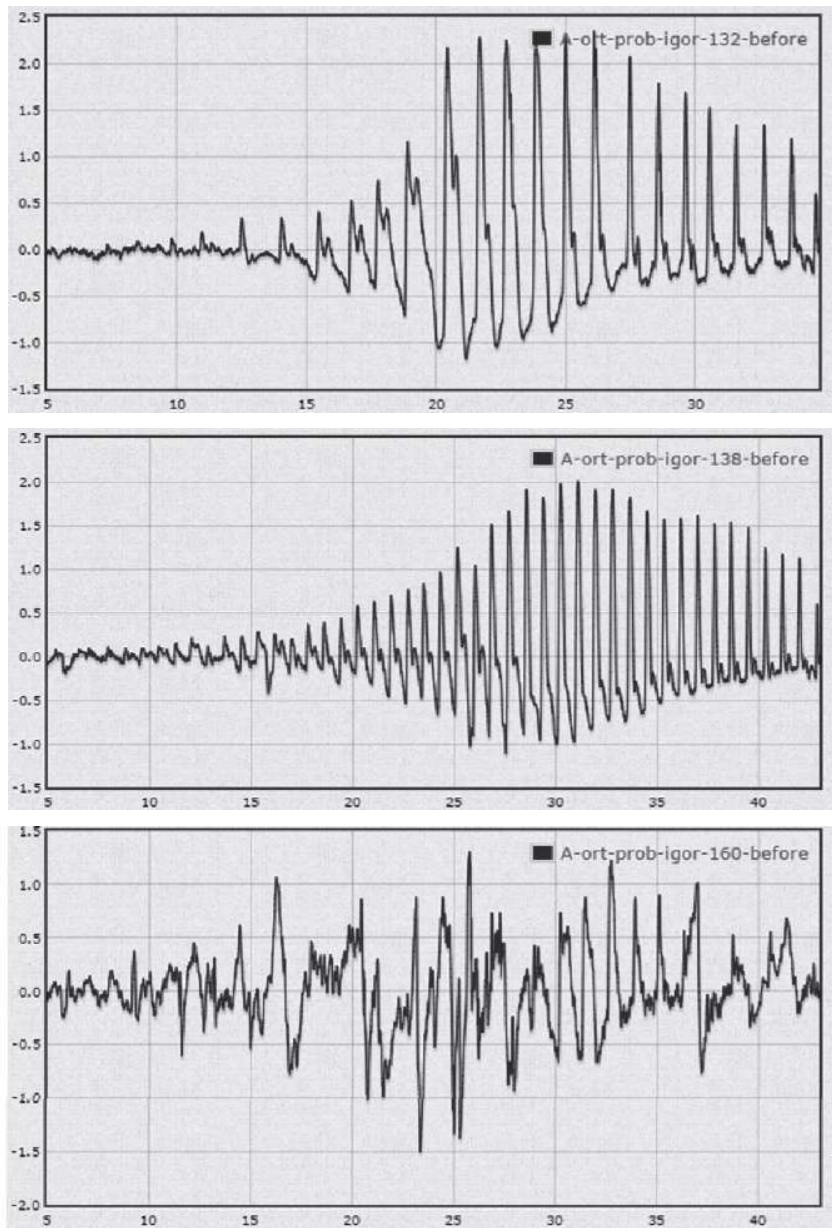

РИС. 1. Осцилограми обстежених 1-ї групи до (лівий стовпчик) та після (правий стовпчик) ортопроби

3. Обстеження проводились за допомогою одного і того ж приладу (ВАТ41-2) для вимірювання артеріального тиску.

4. Аналіз осцилограм проводився за однією і тією ж програмою.

5. Вихідні дані до навантаження відповідали таким осіб 2-ї групи.

Все це дозволяє провести порівняльний аналіз часового та спектрального аналізу осцилограм після виконання проби Руф'є та активної ортостатичної проби.

Порівняльний аналіз динаміки досліджуваних показників на активну ортопробу засвідчив відсутність однотипної (з пробою Руф'є) реакції показників часового та спектрального аналізу осцилограм обстежених (табл. 1). У лівій частині таблиці містяться показники осцилограм, динаміка яких на ортопробу відповідає динаміці на пробу Руф'є, у правій - не співпадає 3 нею. Для оцінки отриманих результатів скористаємося вказівками Р. М. Баєвського про наявність двох
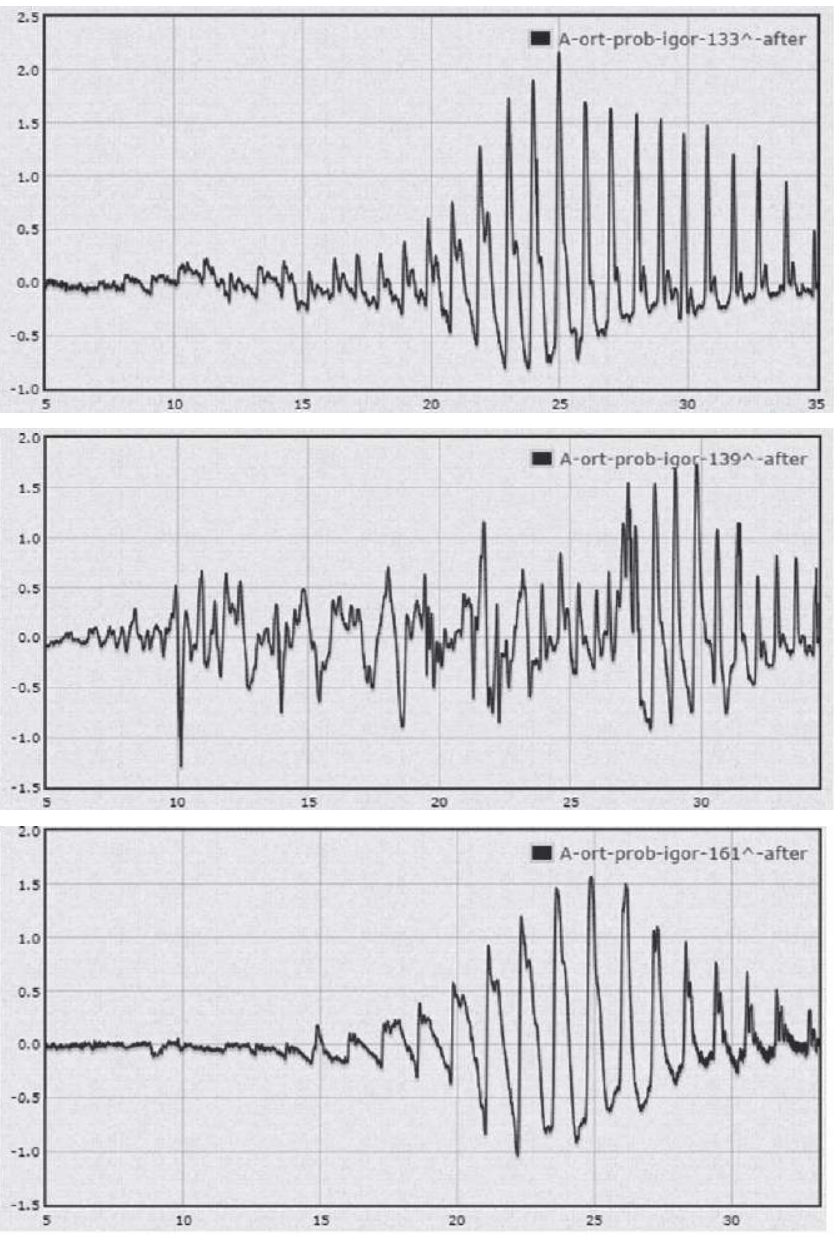
взаємопов'язаних механізмів регуляції серцевого ритму при орто статичних впливах: специфічного (вазомоторного, пов'язаного з регуляцією судинного тонусу) і неспецифічного симпатоадреналового. Вказана інформація дозволяе висловити гіпотезу, що при проведенні активної ортопроби показники, відмічені у лівому стовпчику, зумовлені активацією неспецифічного (симпатоадреналового) механізму А показники, розміщені у правому стовпчику, специфічного (вазомоторного, пов'язаного з регуляцією судинного тонусу) механізму.

Морфологічний аналіз осизилограм. При морфологічному аналізі осцилограм виявилися різнохарактерні реакції у представників обох груп. Для прикладу приводимо осцилограми осіб 1-ї групи (ортопроба) (рис. 1).

Як видно із зазначених рисунків, осциляції у відповідь на компресію плеча манжетою у стані спокою можуть бути різні. Привертають до себе увагу осцилограми у середньому рядку. Вони належать спортсменці, кандидату у майстри спорту

\section{Література.}

1. Бабунц И. В. Азбука анализа вариабельности сердечного ритма [Электронный ресурс] / И. В. Бабунц, 3. М. Мириджанян, Ю. А. Машаех. - Компакт-диск. Электронная версия книги. - Ставрополь, 2002.

2. Баевский Р. М. Вариабельность сердечного ритма: теоретические аспекты и возможности клинического применения / Р. М. Баевский, Г. Г. Иванов // Ультразвуковая и функциональная диагностика. - 2001. № 3. - С. 106-127.

3. Баевский Р. М. Оценка адаптационных возможностей организма и риск развития заболеваний / Р. М. Баевский, А. П. Берсенева. - М. : Медицина, 1997. - 265 с.

4. Вакуленко Д. В. Інформаційна система морфологічного, часового, частотного та кореляційного аналізу артеріальних осцилограму фізичній реабілітації: монографія / Д. В. Вакуленко. - Тернопіль : ТДМУ, 2015. - 212 с.

5. Марценюк В. П. Організація заходів підвищення інформативності діагностики стану серцево-судинної системи 3 використанням методів часового, морфологічного та спектрального аналізу артеріальних осцилограм : методичні рекомендації / В. П. Марценюк, Д. В. Вакуленко, Л. О. Вакуленко. - Тернопіль : ТДМУ, 2015. 6. Михайлов В. М. Вариабельность ритма сердца: опыт практического применения метода / В. М. Михайлов. (изд. 2-е, перераб. и доп.). - Иваново : Иван. гос. мед. академия, 2002. - 290 с.

7. Смирнов К. Ю. Разработка и исследование методов математического моделирования и анализа биоэлектрических сигналов / К. Ю. Смирнов, (спортивна ходьба). Порушення гармонійності пульсацій після ортопроби насторожує щодо стану регуляції периферійного кровообігу. Застосування морфологічного аналізу осцилограм дозволяє ранню діагностику преморбідних станів. Відмічена спортсменка потребує поглибленого обстеження.

Висновки. Застосування осцилографічного методу, математичний аналіз осцилограм (за морфологічним, часовим та спектральним методами) дозволяе оцінити стан специфічного (вазомоторного, пов'язаного з регуляцією судинного тонусу) і неспецифічного симпатоадреналового механізмів адаптації організму до активної ортостатичної проби. Застосування осцилографічного методу при проведенні ортостатичної проби дозволяє раннє виявлення донозологічних і преморбідних станів та оцінку резервних можливостей організму, що допоможе лікарю більш ефективно спланувати профілактичний, діагностичний та терапевтичний процес.

Ю. А. Смирнов. - СПб. : Научно-исследовательская лаборатория «Динамика», 2001. - 60 с.

8. WHO Updates on Cardiovascular Disease [Electronic resource] // WHO official site. - Retrieved from : http:// www.who.int/cardiovascular_diseases/about_cvd/en/.

\section{References.}

1. Babunts, I. V., Miridzhanyan, Z. M. \& Mashaekh, Yu. A. (2002). Azbuka analiza variabel'nosti serdechnogo ritma [The ABC analysis of heart rate variability]. Stavropol' [In Russian].

2. Baevskii, P. M. \& Ivanov, G. G. (2001). Variabel'nost' serdechnogo ritma: teoreticheskie aspekty I vozmozhnosti klinicheskogo primeneniya [Heart rate variability: the theoretical aspects and clinical applications]. Ul'trazvukovaya I funktsional'naya diagnostika (Ultrasound and functional diagnostics), 3, 106-127 [In Russian].

3. Baevskii, R. M. \& Berseneva, A. P. (1997). Otsenka adaptatsionnykh vozmozhnostei organizma i risk razvitiya zabolevanii [Evaluation of adaptive capabilities of the organism, and the risk of diseases]. Moscow: Meditsina [In Russian].

4. Vakulenko. D. V. (2015). Informatsiina sistema morfologichnogo, chasovogo, chastotnogo ta korelyatsiinogo analizu arteriaFnikh ostsilogram u fizichnii reabilitatsii [Information system of morphological, time, frequency and correlation analysis of arterial waveforms in physical rehabilitation] (a monograph). Ternopil': TDMU [In Ukrainian]. 
5. Martsenyuk, V. P., Vakulenko, D. V. \& Vakulenko, L. O. (2015). Organizatsiya zakhodiv pidvishchennya informativnosti diagnostiki stanu sertsevo-sudinnoi sistemi z vikoristannyam metodiv chasovogo, morfologichnogo ta spektral'nogo analizu arterial'nikh ostsilogram [The organization of measures to improve information content of diagnosing the state of the cardiovascular system using temporary methods of morphological and spectral analysis of arterial waveforms] (Guidelines) [In Ukrainian].

6. Mikhailov, V. M. (2002). Variabel'nost' ritma serdtsa: opyt prakticheskogo primeneniya metoda [Heart rate variability: the experience of the practical application of the method]. Ivanovo: Ivanovo State Medical Academy [In Russian].
7. Smirnov, K. Yu. \& Smirnov, Yu. A. (2001). Razrabotka i issledovanie metodov matematicheskogo modelirovaniya i analiza bioelektricheskikh signalov [Development and research of methods of mathematical modeling and analysis of bioelectric signals]. Saint Petersburg: Scientific research laboratory "Dinamika" [In Russian].

8. WHO Updates on Cardiovascular Disease. Retrieved from the [WHO official website, http://www.who.int/ cardiovascular_diseases/about_cvd/. 